\title{
Five years with vocational teacher education online
}

\author{
Steinar Karstensen \& Runar Oudmayer
}

Oslo Metropolitan University, Norway (steinar.karstensen@oslomet.no)

\begin{abstract}
After running online Technical and Vocational Teacher Education (TVTE) classes for five years we have collated our experiences and thematically probed them through the following questions: (1) What are the pedagogical and didactic considerations with online TVTE (2) What are the technical challenges? (3) What opportunities and limitations have emerged? (4) How do the teachers and students experience online teaching? (5) How do teachers compare online teaching with on-campus teaching? Our experiences where accumulated through the TVTE in the Technological Programme (TP) at Oslo Metropolitan University (OsloMet), and are based on both teacher and student responses, learning logs, evaluations, and anonymised student data.

In short, online study has helped us to achieve a larger geographical spread of students. The students experience online study as flexible, as they do not have to meet on campus every week. The technology has worked and allows for further development of the subjects being offered. It appears to be an equal opportunity offered compared to the campus-based with greater flexibility according to where the student is located. The workload also appears to be manageable for teachers who are engaged in the online class environment.
\end{abstract}

Keywords: online learning, distance learning, vocational teacher education 


\section{Introduction}

At the start of the autumn semester of 2014, vocational teacher education in technology subjects (TP) initiated its first online programme. The purpose was to offer more flexible learning platforms to students.

In the digital strategic plan from OsloMet (2017) they say that in a digitalised world, the new demand for services is set. A world where the individual expects the flexibility of services that can be made available where they are, and when they need them. Something that should reflect in a simpler everyday life that can be adapted to the individual's life situation and needs (OsloMet, 2017).

Since the original start-up, four classes have completed a three-year bachelor education in spring 2020. New classes are started annually. Initially the class consisted of just under 20 students, now there are classes of 30 students or more. Teaching staff have also increased accordingly, from just one teacher in the first few years, to a team of five led by a class teacher responsible for the professional subject, where up to four vocational subjects per class are also attended by different time-based vocational teachers.

The purpose of this article is to systematically correlate online teaching experiences with online teaching. The following questions are addressed in this paper: (1) What are the pedagogical and didactic considerations with online Technical and Vocational Teacher Education (TVTE)? (2) What are the technical challenges? (3) What opportunities and limitations have emerged? (4) How do the teachers and students experience online teaching? (5) How do teachers compare online teaching with on-campus teaching?

Oslo Metropolitan University (OsloMet) offers TVTE in eight of their nine educational programmes. This article concerns technological programmes (TP), which is a generic term covering four educational programmes: the programme for Building and Construction (BA), the programme for Electricity and Electronics (EF), the programme for Service and Transport (SS) and the programme for Technical and Industrial Production (TIP), all grouped together under the collective term technological programmes (TVTE-TP). This training is intended to help meet the requirement for a combination of teaching and vocational skills (UDIR, 2017).

The educational programmes enable students to obtain the qualifications required to work as teachers in several individual trades within the overall category. For example, the EF programme is made up of electricians, electronics engineers, telecommunications technicians, etc. Together the four educational programmes represent 109 different trades.

The programme is a three-year bachelor's degree which enables practitioners of a profession to qualify as Technical Vocational Education and Training (TVET) teachers. It is made up of a total of 180 credits, with 60 credits representing the pedacogical subject base and 120 credits for technical and vocational subjects. 
Five years with vocational teacher education online

Learning outcomes are divided into knowledge, skills and general competence in the same way that the Norwegian National Qualifications Framework (NKR) (NKR, 2009) for lifelong learning is based on the European Qualification Framework (EQF, 2012).

TVTE-TP students typically have an average age of 40 and hold trade certificates or skilled craftsman's/journeyman's certificates and most of them have several years' practical experience in their professions (Karstensen, 2014).

\section{Organisation of the TVTE-TP programme}

The TVTE-TP programme started as an ordinary campus study in 2006 and was expanded to include an online programme in 2014. Both standard and digital programmes normally begin with a five-day on-campus gathering to allow students and staff to become acquainted with each other and the course. After this, the on-campus class continues with weekly physical gatherings. The online class however, has two physical gatherings over a period of two days per semester, and all other activities are conducted online. They also establish study groups of four to six people at the first physical meeting across the programmes. The study groups meet in different ways depending largely on the geographic location of the individual. The intention is that they should remain together as a group for the rest of the course. During the course, there are tasks to be solved individually and in study groups, in addition to supervised professional training. The class has joint education in the programme of professional study but is divided into their respective educational programmes when it comes to technical and vocational subjects (Karstensen, 2014).

Teachers of pedagogical subjects teach the groups frequently and also function as year group coordinators. Consequently, they have additional contact and more extensive experience with the students online. Lecturers in technical and vocational subjects (who normally just have a part time teacher position at OsloMet) work with their students within their educational programme and normally only have one online meeting, in addition to online academic supervision. The number of students in the four technical programmes included in this survey ranges from 3-4 up to 12-15 in each group. A lot of the teaching is conducted in such a way that both teachers of professional studies and lecturers work with the same work requirements.

The 2014 group was the first online class. At start-up, it was planned that the online course would be the same as the one offered on-campus. It was also planned that there would be some joint teaching for the two courses, in that the online class could take part in on-campus activities. The following shared platforms were mainly used: Fronter as a Learning Management System (LMS), Adobe Connect as a synchronous communication program and Microsoft Office 
support programs. The first year is well documented in From campus to online learning (Karstensen, 2015).

A new group started in 2015. It followed practically the same arrangement as the first-year group. During the first year, the teachers experienced that they couldn't find any joint solutions for both the online and on-campus teaching. With the limited equipment and resources available, teachers had a choice between solely online teaching or physical teaching on-campus.

Since they wanted to use multimedia texts to a greater extent than earlier, Wikispaces was included as a new platform in addition to those they already had. Through this, they discovered that it was fully possible to have study groups that did not have any physical gatherings. The groups established themselves independently, but the geographical location of the members was no longer important.

The 2016-year group was re-organised with fewer gatherings for the whole class and more groupwork. This was a didactic adjustment implemented to achieve more engagement among the students. A normal gathering-day would therefore start with one to two hours of joint teaching for the whole class followed by groupwork and another joint meeting of approximately one hour at the end of the day.

The students used the LMS Fronter and Wikispaces from start-up. Gradually, OsloMet's Office 365 replaced Wikispaces, and Fronter was replaced by Canvas. In line with the flipped classroom method, some of the teaching material was recorded on video and made available to students before the meeting and could thus be used to jointly address and discuss issues about the content that the students had engaged with beforehand.

Based on past experiences we saw a need for an even more flexible programme, independent of startup, location and time requirements (Foss, Gustavsson, Johansen, Karstensen, Rodheim, Schneider \& Sønsteli, 2011). With this as the starting point, a plan was created for the 2017-year group to prepare the students to start their programme. Many of these materials were made available via an Open edX solution. Information was distributed to all students who had been accepted for admission and they had the opportunity to work through the material prior to the start of the semester. An important factor enabling students to find possible collaborators and ideally to have established a study group by the first day of the course. The starting week, which was normally five days, was reduced to two. Office 365, Wikispaces and Canvas were also important platforms for this group for the interaction among students, and between students and teachers.

The 2018-year group followed the same arrangement as the previous group, however based on experiences from the previous year, information in preparation for the course start was shared through a single webpage. We found that the use of multiple platforms in 2017 created some confusion for students in that it 
was difficult to know where to find what. In addition, some of the students had issues with registration and in accessing the different university platforms. By using a blog webpage that did not require login, we reduced a lot of administration work related to student registration and access into the system. On the other hand, the options available to build student-to-student relationships were limited in the blog webpage. A reason for having a flexible starting date was to give those students who could not attend the starting week for various reasons the flexibility to enrol at a later date. According to Werhner (2010) there is a growing demand for distance education, as students find that the flexibility of online classes allows them to combine their studies with other life commitments, such as family and job. There may be some confusion in using the concepts of distance learning, especially where online and web-based learning can also be used by campus-based services as an education tool. We do not want to distinguish between use in the classroom or as part of distance learning but describe and use these as a tool in our context. Colleges and universities see distance education as a means to increase students enrolment without the additional expense of building more classrooms or adding staff (Werhner, 2010). What type of online learning should be used - synchronous (live time) e-learning (e.g., video conferencing, live text or audio chat, etc.) or asynchronous (at one's own pace) e-learning (e.g., email, blogging, etc.) - depends on several factors. Online synchronous communication, i.e. via videoconferencing systems, can be less convenient and more intimidating for students who prefer flexibility in both time and space. However, Woodcock, Sisco, and Eady (2015) suggest that synchronous communication allows greater coherence and focus on tasks, increased participation, and more frequent completion of students' work and courses than in studies where asynchronous communication is the main alternative.

To define distance education Moore (2013) used the theory of transactional distance. In this theory, distance education is not simply a geographic separation of learners and teachers, but, more importantly, a pedagogical concept. It is a concept describing the universe of teacher-learner relationships that exist when learners and teachers are separated in space and/or in time. With separation, there is a psychological and communicative space to be crossed, a space of potential misunderstanding between the inputs of teachers and those of the learners. This psychological and communicative separation is framed in terms of transactional distance. One set of variables that determine transactional distance are the elements in the course design, or the ways in which the teaching programme is structured so that it can be delivered through various communicative media (Moore, 2013). In the policy for digital transformation at OsloMet (2018), new technology enables student-active learning methods that ensure both increased learning outcomes for the student and a more motivating teaching environment for the teacher. In an article that has analysed and mapped out trends in online learning, Zawacki-Richter och Naidu (2016) found that learning is seen 
as a social process, facilitated by interaction among participants. The provision of opportunities for interaction, communication and collaboration between students and their teachers, as well as among students, via two-way communication, is proposed as a constituent element of distance education. In such settings, learning and teaching are the result of careful design and orchestration of the learning environment, the communication processes, the learner support and use of learning materials. Distance education demands and needs innovative solutions to the challenges posed by the physical separation of the learners from their teachers (Zawacki-Richter \& Naidu, 2016, p. 249).

In their review of the factors influencing E-Learning, Nortvig, Petersen and Balle (2018) show that some factors seem to dominate more than others - for example, the educator's presence in online settings, the interactions between students, teachers and content, and designed connections between online and offline activities, as well as between campus-related and supervised professional training-related activities. This suggests that it is not just the online format alone that affects learning outcomes, satisfaction and student retention. However, students' experiences of the learning community appear to be significantly influenced by the online element. The review also sheds light on the paradoxes of the online environment, as the software used creates new opportunities for interactivity between student and content, between student and teacher, and among students themselves. At the same time we have e.g. learning platforms (LMS) that are also independent of students' geographical location, asynchronous participation and limited visual contact (Nortvig et al., 2018, p. 50). Creating a sense of belonging to a meaningful learning community is therefore an important factor for learning experiences, especially because it is difficult to make their social presence perceptible. Nevertheless, student-student interactions and collaborative activities are not necessarily the sole prerequisite for online students to feel part of a learning community. As Moore (2013) also highlights, other variables exist besides those of teaching and learning. Moore mentions distance education administration, distance education history, distance learner motivation. Some of them are more global than others, such as transactional distance and distance learner motivation (Moore, 2013). Studies comparing face-to-face teaching to online and/or blended learning reveals that no inherent features of any of the three teaching formats produce either better or poorer learning outcomes for students. What leads to one outcome over another is not the format itself, but is circumstantial and context-dependent (Nortvig et al., 2018; Werhner, 2010). There are different perspectives as to what quality in online learning is and should be. There are also major differences between professional and social needs and achievements within different fields of study and individual subjects, and there are human resources related to the interests and technological skills that are taking place. The study situation for a student in an on-campus course is different than for a student who participates in online education (Nordkvelle, Netteland \& Fossland, 2013). The 
interaction between the teacher and learner, and among learners, affects the quality and success of online learning, and the learner's ability to master the outcomes associated with the targeted content or skill area, as well as the broad outcomes of higher education, such as critical thinking, problem-solving, and communication (Association of American Colleges and Universities, 2015, in Andrade, 2015, pp. 2-4). In adult education, students and teachers should share a common responsibility and be more equal in achieving a good result (Holt \& Stokke, 2014). This is in line with how adults view themselves as self-governing individuals. It is the practice of adult education, separate from the education of children, to treat the transaction between learning and teaching as the mutual responsibility of students and teachers. 'The role of the teacher is actually redefined as that of a process consultant, resource manager and co-investigator.' (Knowles, 1990).

\section{Perseverance and dropouts}

Perseverance is necessary to successfully complete a course online. Dropout rates in online and distance education are higher than in campus. Furthermore, student satisfaction has been shown to be a very intuitive and straightforward variable that is positively associated with perseverance. Factors related to dropout rates do not always lend themselves to easy measurement, as these might include any number of factors from scheduling conflicts, family issues, and financial problems, to technical issues and academic integration (Weidlich \& Bastiaens, 2018). Furthermore, high dropout rates do not only apply to online classes. Lillevik Rokkones, Landro, and Utvær (2019) discuss dropout rates in TVTE at the Norwegian University of Science and Technology (NTNU), concerning campus classes. Their study shows that dropout rates vary greatly between annual cohorts. The 2007 -cohort in their study had a 34.5 per cent dropout rate, yet for the 2013 cohort the dropout rate was 11.1 per cent. The average dropout rate across the eight cohorts that started between 2007 and 2014 was 25.8 per cent. Compared to other teacher training programmes, TVTE is different in that occasionally the dropout rate can be especially high early in the course.

A study of dropouts and persistent learners by Park and Choi (2009) showed statistical differences in their perceptions of family and organisational support, satisfaction and relevance. From their framework it was possible to predict whether someone would dropout or persevere, which includes levels of family support, organisational support, satisfaction, and relevance, in addition to individual characteristics. Organisational support and relevance were shown to be particularly predictive (Park \& Choi, 2009).

\section{Methodology}

The teachers at our campus have a dual role, firstly as educators of vocational teachers and secondly as researchers into their own practice (Hiim, 2010; Tiller, 
2004). As researchers, our role is to develop theoretical knowledge through researching our own practice.

According to Hiim (2010), the basic requirement of research work is that it should contribute to the development of knowledge. By researching our own practice as educators of vocational teachers our aim is to develop our knowledge of students' learning through the development of their learning strategies.

From the very first intake, the students of our online programme were aware that this was a new and novel opportunity to study at OsloMet online and that therefore the programme would be undergoing continuous development. It was vitally important that students constantly gave feedback on what worked and what could be done differently. From this perspective, the course design and implementation has been characterised by action-oriented thinking. At the same time, the development work is also characterised by a phenomenological approach, through which data from student feedback has been systematically analysed. The empirical data are obtained through reflection from both teachers and student logs, feedback, dialogue and participation in the programme.

In addition, the methodological approaches have been heuristic. According to Moustakas (1990), heuristic research begins with questions that need to be attended to and represents a systematic search that involves seven concepts: identifying with the focus of inquiry, self-dialogue, tacit knowing, intuition, indwelling, focusing, and the internal frame of reference. These concepts assist the researcher in reflecting on his/her hunches, thoughts, images, and deeper knowledge, and connecting to the greater meaning of the phenomena being researched. Heuristic inquiry does not exclude the researcher from the study; rather it incorporates the researcher's experiences with the experiences of co-researchers. The researcher is required to have a direct experience of the phenomenon in question (Douglass \& Moustakas, 1985; Moustakas, 1990, p. 38).

The article is based on the materials available from 2015 to 2019. The materials were gathered through reflection logs, feedback and dialogue with and from students and teachers participating in the programme. Statements from the dialogue with the teachers are given in the results with informant 1 to 5 (Informant 1-5). The results also include data retrieved from the administrative system for comparison with the on-campus class in relation to demographics, admission and completion.

\section{Results}

Our results show that the online study has helped us to achieve a broader geographical spread in relation to student enrolments. The students experience our programme as a flexible study where they do not have to meet on campus every week. The technology has worked well so far and allows for continuous and further development. It appears to be on an equal footing academically with its 
Five years with vocational teacher education online

campus-based alternative but offers greater flexibility according to where the student is located. The workload also appears to be manageable for the teacher who is engaged in the online class. We go deeper into this in the following section to answer our initial research question.

\section{What are the pedagogical and didactical considerations of the online TVTE?}

When the decision to implement online studies was first made, a targeted effort was made to find good ways to design and implement the online programme for our TVTE-TP programme. What constitutes good pedagogy and didactics for online studies? Should the studies be 'gathering-based' or entirely online?

The analysis of our data shows that pedagogical and didactical challenges exist and must be considered when carrying out online teaching, although our starting point for facilitating online teaching was; 'It must be possible to do online what we do in the classroom'. We see that there has been a gradual didactical adaptation to prevent lessons from becoming monotonous and uninspiring. 'I don't hold lectures very often; we have one to one-and-half-hour sessions followed by groupwork and discussions. The students then present their work.' (Informant 5)

All the teachers are aware that special adaptations must be made in their pedagogical and didactic approach towards online teaching. The implementation of online teaching is more than just moving the classroom online. The retainment of 'study groups' has functioned well and has given teachers some room to alternate between lectures and group work. As with on-campus teaching, individual adaptations must be made from year to year. Some students say there is too much group work, while others say there is too little, etc. The content of the lessons is also significant when choosing the approaches to use.

The extent to which a learning environment can be established between students, and between students and teachers in any given on-campus class, and whether its absence or reduction in online classes affects the class and each individual student, continues to be a major issue. We see that teachers who have a significantly smaller number of hours online miss this environment to a greater extent than teachers who have the students frequently and/or long sessions online. The students, however, do not seem equally concerned with this. They claim that they form good relationships with each other, despite the large physical distance between them. Additionally, they find that their groups cooperate well, both online and during physical gatherings.

A trial with video feedback on students' work was a form of pedagogical adaptation to promote stronger contact between teacher and student. This proved to be successful and was well-received by the students. 
What are the technical challenges?

Surprisingly, there have been very few technical problems with the online platforms and solution that we have used. Generally, the technical problems have been perceived as user errors or have been caused by inexperienced users.

The subject-specific hourly paid teachers find that they have more problems than the teachers in the professional studies precisely because they lack experience in dealing with emergency situations during classes since they only have a few sessions during the semester. For inexperienced teachers, small problems can quickly become quite large. Like for example that the sound goes away, the microphone does not work, the camera does not show a picture, etc. even though it is basically just pressing the right buttons and is arranged relatively quickly, it becomes stressful.

A considerable amount of time is set aside during the start of the programme and the initial attendance on campus, to fine tune the technical solutions and equipment needs the students must fulfil. 'However, this also relies on the students having the right equipment in place; a good headset, camera and satisfactory internet connection.' (Informant 5)

During the campus meeting, students can test the online tools and the webbased solutions. After this, few problems are encountered. It is also important that the students have adequate infrastructure at home. Success in distance courses is associated with the learners' ability to take responsibility for controlling the factors that affect their learning (Andrade, 2015).

Student feedback suggests that they find it equally fine to meet both on campus and online, but they also think it is okay to do so asynchronously. It seems like it is a combination that works well. It also appears that they are afraid that all the course elements will be asynchronous, or that they will never meet on campus.

\section{What opportunities and limitations have emerged?}

There is considerable agreement among the teachers involved that the flexibility of online courses offers many opportunities, first and foremost because the students do not need to travel to the university campus, but also because it is possible to present the content in a more flexible (asynchronous) way. 'The course is wherever you are. I believe that online courses attract more students than oncampus courses only. I believe that more students think they will be able to do the course because it's online.' (Informant 1)

The students spend a lot of time working in groups online and the groups have regular online meetings. Teachers also say that by making themselves more available, it reduces the risk of workload piling up within standard working hours. Questions can be dealt with, then and there, and enables them to give the 
students more effective feedback. This means that the students can receive swift asynchronous feedback.

The students' experiences with online teaching facilitate rapid initiation of the follow-up and academic supervision of students undergoing supervised professional training. So far, the feedback for this follow-up has been very good.

OsloMet has gradually introduced the use of Office 365 at all levels. As a result, we have many excellent shared solutions to use for digital services. This also gives our students many possibilities to develop good digital skills to take into their own classrooms.

Numerous possibilities exist for the further development of our online courses. They can vary in content, shape and form. One possibility is to develop the option for asynchronous participation. At present, the online teaching resembles more of an 'online classroom'. We envisage that the content could possibly be adapted with finished content components for students to review and complete at their own pace. This transition to a more asynchronous course would likely lead to the perception that the course is even more flexible as well.

\section{How do the teachers and students experience online teaching?}

The teachers clearly express that they appreciate the possibility to work through online teaching, with all the challenges and possibilities it presents. They indicate that it is exciting to work with online teaching and to be allowed to be involved in its further development. 'I think it's great fun to be involved in this.' (Informant 1)

From early on in their studies, the students gain good user experiences that also benefit the teachers' practice. Those teachers with less experience often find that students can help them when user problems arise. Even though students have expressed that there are many platforms to relate to, it is evident to the teachers that the students seem confident and satisfied.

In terms of content and results, several of our interviewees confirm that the teachers find online teaching to be just as rewarding as on-campus teaching, even though it may feel a bit unusual to not have the same contact with the class as in a physical classroom.

There are several indications that students are very comfortable with the study group work, which is mainly done online. Occasionally, the teachers have the impression that the students do not really think about being in a classroom or in the online platform AdobeConnect.

One goal that we have continuously fallen short of has been gathering several classes online for one simultaneous lecture. To date, our experiences with this have not been particularly good, and the students have reported that they do not greatly benefit from such digital gatherings.

The software that we use is essentially for large lectures (and webinars). Therefore, it requires much more management and is mainly used for monologue style 
lecturing. There are features however, such as random grouping, that allow parts of the lessons to be more flexible and comprehensive.

\section{How do teachers compare online teaching with on-campus teaching?}

When we asked the respondents for their views on how on-campus and online teaching differ, we found that the main trend was that they strongly emphasised the possibilities in on-campus teaching, while in the case of online teaching. Respondents mainly talked about it in terms of its disadvantages. 'I'm certain that online teaching equals on-campus teaching, but it needs to be planned differently.' (Informant 3)

The common denominator between the respondents is that they emphasise fewer opportunities to form social relationships. The students, however, have only given a small amount of feedback, and it does not suggest the same issue. They say they feel they have good relationships with fellow students.

The teachers see some advantages with online teaching including that they consider it as 'equal' to on-campus teaching, and that it offers some possibilities that are not so easily attainable through on-campus gatherings. Groupwork often involves the sharing of reflections and thoughts with your 'neighbour' (the person physically sitting next to you at a particular time). With online teaching, teachers can randomly split groups each time or create groups that they want to keep for a short period of time (this may depend somewhat on the context).

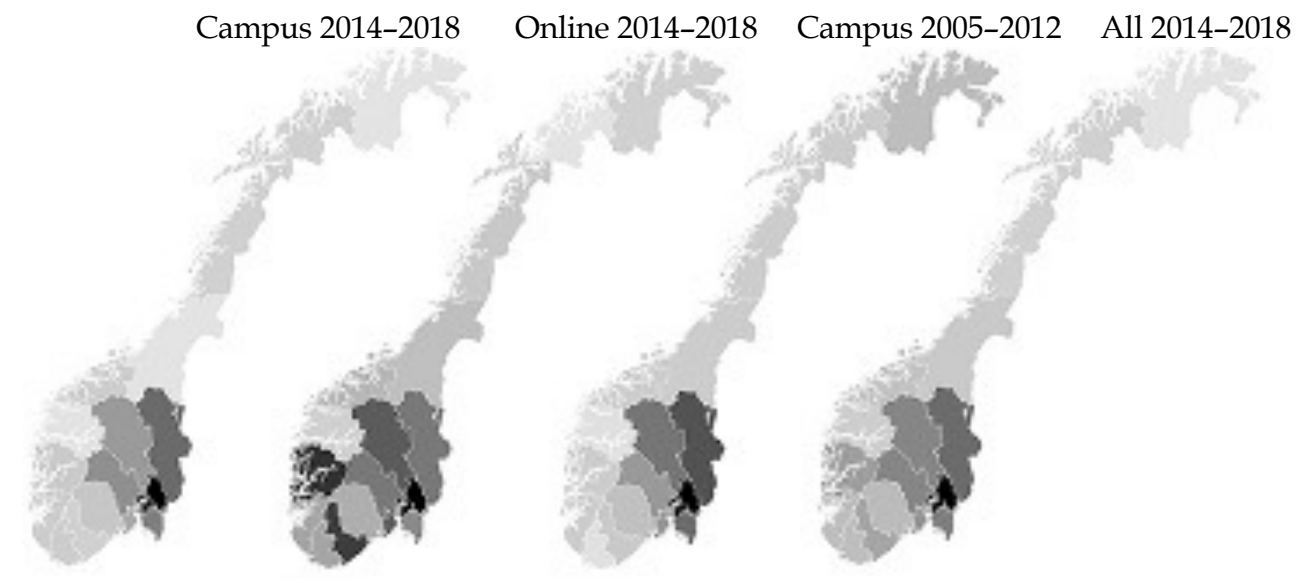

Figure 1. Graphic representation of regions (counties) in Norway where the students attending the on-campus and online programmes offered came from before and after the online programme started.

The graphic presentation in Figure 1 shows the distribution of students based on geographical regions (counties) in Norway. The data are from the student administrative system. The darker the counties, the higher the density of students. The 
grey tone on the four maps are scaled differently based on the maximum number of students in the indication. As such, the presentation cannot be used to indicate which type of study programme has the highest density of students. This has been done to promote visualisation of the distribution and not the number of students on each type of programme. The first two maps show the domiciles of students on campus and online from 2014 to 2018, respectively. As the maps show, the density of students around eastern-central areas of Norway or near OsloMet is distinctively related to the on-campus programme. The online programme also has students in the same local community, but the density is higher towards the south and west of Norway. The last two maps illustrate the distribution before the online programme was offered, as well as the campus programme, between 2005-2012, and the total distribution thereafter (that is, the on-campus and online programmes combined). As the maps show, the online programme has contributed to a larger possible recruitment area for TVTE and thus contributed towards the societal mission of offering TVTE throughout Norway, in collaboration with the Norwegian University of Science and Technology (NTNU) (Grande, Lyckander, Landro \& Rokkones, 2014).

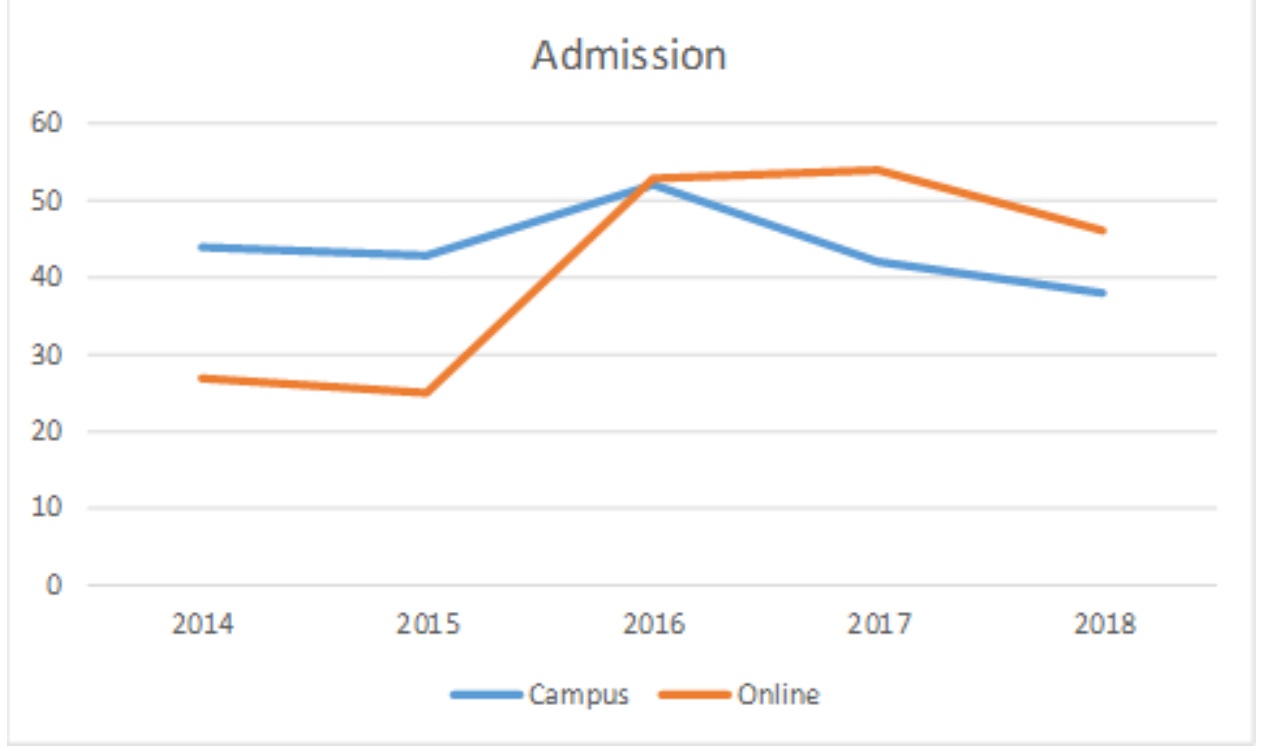

Figure 2. Admission on campus and online.

The graphs in Figure 2 show the number of students who have been offered a place on either on-campus or online courses during the period. In addition to offering a flexible course of study for students through the online programme, one of the objectives was to enrol more students so that OsloMet could meet the quota for the number of students that are expected to graduate each year. The target figure (in 2012) for TVTE-TP was 60 students. Since the typical age of those admitted to this type of programme was between 40 and 50, this was an 
impossible task to achieve. As the graph shows, the total number of admissions increased from the first year for the online programme. In the course of the first two years, the on-campus and online programmes became just as popular (2016). The following two years, however, admission to the online programme surpassed that of the on-campus programme. However, it does not appear that the online programme 'steals' students from the on-campus programme - rather, they complement each other. In 2018, admission rates dropped for both types of programmes, the cause for which has not been assessed.

Table 1. Online TVTE-TP 2014 to 2018.

\begin{tabular}{|r|r|r|r|r|r|r|r|r|r|}
\hline & \multicolumn{7}{|c|}{ Online all field of study } & \\
\hline & Active & Completed & Withdraw & Transfer & Leave & Ended & Drawn & Expired & Total \\
\hline $\mathbf{2 0 1 4}$ & & $63 \%$ & $4 \%$ & $7 \%$ & $0 \%$ & $15 \%$ & $11 \%$ & $0 \%$ & 27 \\
\hline $\mathbf{2 0 1 5}$ & & $68 \%$ & $16 \%$ & $0 \%$ & $0 \%$ & $4 \%$ & $8 \%$ & $4 \%$ & 25 \\
\hline $\mathbf{2 0 1 6}$ & $51 \%$ & & $9 \%$ & $9 \%$ & $2 \%$ & $13 \%$ & $15 \%$ & $0 \%$ & 53 \\
\hline $\mathbf{2 0 1 7}$ & $61 \%$ & & $7 \%$ & $7 \%$ & $2 \%$ & $9 \%$ & $13 \%$ & $2 \%$ & 54 \\
\hline $\mathbf{2 0 1 8}$ & $59 \%$ & & $7 \%$ & $7 \%$ & $0 \%$ & $11 \%$ & $22 \%$ & $0 \%$ & 46 \\
\hline & & & $8 \%$ & $8 \%$ & $1 \%$ & $11 \%$ & $15 \%$ & $1 \%$ & 205 \\
\hline
\end{tabular}

Table 2. Campus TVTE-TP 2014 to 2018.

\begin{tabular}{|r|r|r|r|r|r|r|r|r|r|}
\hline & \multicolumn{7}{|c|}{ Campus all field of study } & \\
\hline & Active & Completed & Withdraw & Transfer & Leave & Ended & Drawn & Expired & Total \\
\hline $\mathbf{2 0 1 4}$ & & $59 \%$ & $2 \%$ & $2 \%$ & $0 \%$ & $14 \%$ & $20 \%$ & $2 \%$ & 44 \\
\hline $\mathbf{2 0 1 5}$ & & $58 \%$ & $12 \%$ & $9 \%$ & $0 \%$ & $14 \%$ & $7 \%$ & $0 \%$ & 43 \\
\hline $\mathbf{2 0 1 6}$ & $71 \%$ & & $6 \%$ & $8 \%$ & $2 \%$ & $6 \%$ & $6 \%$ & $2 \%$ & 52 \\
\hline $\mathbf{2 0 1 7}$ & $79 \%$ & & $5 \%$ & $2 \%$ & $2 \%$ & $2 \%$ & $7 \%$ & $2 \%$ & 42 \\
\hline 2018 & $82 \%$ & & $5 \%$ & $5 \%$ & $0 \%$ & $5 \%$ & $3 \%$ & $0 \%$ & 38 \\
\hline & & & $6 \%$ & $5 \%$ & $1 \%$ & $8 \%$ & $9 \%$ & $1 \%$ & 219 \\
\hline
\end{tabular}

Tables 1 and 2 show the total number of applicants for campus-based and onlinebased courses. Bachelor's degree programmes for vocational teachers last for a period of three years, but since the article covers a period of five years, the last three cohorts had yet to complete their studies. The 2016 group had started work on their bachelor's theses in 2019. The 2017 group were now in their fourth semester, and the 2018 group were in their second. We have listed the cohorts that were still active when this study was conducted under 'Active'. Those who had completed their course are highlighted in the 'Completed' column. 
The figures show that during the five-year period, 59 per cent of students completed the on-campus programme and 65 per cent the online programme. If we look at the cohorts that were still active, the picture is somewhat different. It shows that overall, 77 per cent of those who applied for admission on campus were still active. For the online programme, however, the figure is significantly lower with 57 per cent still active. As shown in Figure 2 above, the interest for online-based studies has sharply increased, and from the 2016-year group onwards there have been more applicants for online-based studies than for on-campus studies. The demographic composition of online students is different compared to those who apply for on-campus programmes. We also know that, for example, accessibility and flexibility mean a lot to our applicants for online-based studies.

We do not know for certain why the number of applicants for online-based studies has been declining. From our data, we can see that the dropout rate is higher among these applicants early in the course. For example, a significant number of students have refused the offer (withdrawn) or had their admission to a course or specific programme of study withdrawn (Expired - Students who have not completed the examination or applied for extended admission to a course or specific programme of study). We do not have exact data on this, but there is reason to believe that this happens relatively early in the programme (from the first day up to the beginning of the second semester). Among those who have dropped out from the course during their period of study, we also see a significant increase in the number of applicants for online studies.

Of those who apply for a transfer from on-campus to online or vice versa, it is largely the same for both programmes. For students who are on leave of absence, there is no significant difference.

Nevertheless, if we look at those who have lost their right to admission to a course or specific programme of study (withdrawn), we see that the dropout rate is slightly higher for the online programmes but follows the same trend.

\section{Summary}

After 'five years online' the offer of online studies has had positive results. Admission is offered to students across a wider area in Norway without this seeming to affect the number of students who would normally be admitted to campus programmes.

Teachers involved in online studies consider their contribution and participation in a new programme as positive. They find it interesting and challenging to be allowed to help establish new pedagogical practices in a field that in many ways differs from on-campus classroom teaching, but also has many similarities. Both teachers and students emphasise the opportunity for flexibility that the online programme provides. We see that the online programme attracts many 
students who would not normally have time or the possibility to complete the course of study if they followed the ordinary campus-based programme.

The purpose of this study has been to obtain a picture of the first five years with both online and campus-based studies. The study uncovered many interesting areas that are well worth looking at in more detail, such as a greater focus on what is possible synchronously versus asynchronously, and how to establish good student relationships in the beginning that will make students feel safe and feel looked after and taken care of in an online environment. At the same time, it important that the students also contribute (preferably with their learning work) in a digital online environment and gain expertise on this.

\section{Notes on contributors}

Steinar Karstensen is an Associate Professor at the Department of Vocational Teacher Education at OsloMet - Oslo Metropolitan University, Norway. His area of interest is technology in work and learning. The field of technology and learning focuses on the development of technological competence, digitalisation, automation, robotisation, simulation, and relations between technology and learning in different professions, and what implications this has for vocational education in secondary school and for vocational teacher education. He is also the leader of a research group with the same area of interest.

Runar Oudmayer is Assistant Professor at the Department of Vocational Teacher Education at OsloMet - Oslo Metropolitan University, Norway. His area of interest is technology and information technology, ICT in teaching and learning, digitalisation, robotisation, virtual reality, and simulation impact on vocational teacher education. 
Five years with vocational teacher education online

\section{References}

Andrade, M.S. (2015). Teaching online: A theory-based approach to student success. Journal of Education and Training Studies, 3(5), 1-9.

Douglass, B.G., \& Moustakas, C. (1985). Heuristic inquiry: The internal search to know. Journal of Humanistic Psychology, 25(3), 39-55.

Foss, S., Gustavsson, A., Johansen, F., Karstensen, S., Rodheim, S., Schneider, M., \& Sønsteli, S.T. (2011). Kvalitet i flexibelt lärande: En tekstsamling for bedre utdanning med digitale medier [Quality in flexible learning: A text collection for better education with digital media]. Karlstad: UNISKA Universitetsalliansen Inre Skandinavien.

Grande, S.Ø., Lyckander, R., Landro, J., \& Rokkones, K. (2014). Fram i lyset! En kartlegging av status og behov for lærerutdanning for yrkesfag [Accentuate! A survey of the status and need for teacher education for vocational subjects].

Retrieved 25. June, 2020, from https:/ / www.ntnu.no/documents/150035/20502917/Fram+i+lyset!/60886d96-25e0-4ef3-b67da153770ef7c4

Hiim, H. (2010). Pedagogisk aksjonsforskning: Tilnærminger, eksempler og kunnskapsfilosofisk grunnlag [Pedagogical action research: Approaches, examples and the philosophy of knowledge]. Oslo: Gyldendal Akademisk.

Holt, J., \& Stokke, K.E. (2014). Teaching literacy, numeracy and ICT to adults: The basic skills programme (BKA program) for workers in building construction (bricklayers, carpenters and foundation workers). Paper presented at the ATEE ANNUAL CONFERENCE 2014, Brussel.

Karstensen, S. (2014). What do the teacher training students see when they look and what do they say they see when they are out on the observation in school for the first time. Paper presented at the ATEE ANNUAL CONFERENCE 2014, Brussel.

Karstensen, S. (2015). From campus to online learning - experience from the first year of online training in Technical and Vocational Teacher Education (TVTE). Paper presented at the ATEE ANNUAL CONFERENCE 2015, Brussel.

Knowles, M.S. (1990). The adult learner: A neglected species (4th ed.). Houston: Gulf Pub. Co.

Lillevik Rokkones, K., Landro, J., \& Utvær, B.K. (2019). Bachelorutdanning for yrkesfaglærere, i et historisk og utviklingsorientert perspektiv [Bachelor programme for vocational teachers, in a historical and development-oriented perspective]. Nordic Journal of Vocational Education and Training, 8(3), 141-159.

Moore, M.G. (2013). Handbook of distance education (3rd ed.). New York: Routledge.

Moustakas, C. (1990). Heuristic research: Design, methodology, and applications. Thousand Oaks: SAGE Publications.

NKR. (2009). Nasjonalt kvalifikasjonsrammeverk for høyere utdanning [National qualifications framework for higher education] (NKR). Retrieved 25. June, 
2020, from https://www.regjeringen.no/no/tema/utdanning/hoyere-utdanning/nasjonalt-kvalifikasjonsrammeverk/id564809/

Nordkvelle, Y., Netteland, G., \& Fossland, T.M. (2013). Kvalitet i fleksibel høyere utdanning: Nordiske perspektiver. Trondheim: Akademika.

Nortvig, A-M., Petersen, A.K., \& Balle, S.H. (2018). A literature review of the factors influencing e-learning and blended learning in relation to learning outcome, student satisfaction and engagement. Electronic Journal of e-Learning, 16(1), 46-55.

OsloMet. (2017). Digital strategic plan. Retrieved 25. June, 2020, from https://www.oslomet.no/en/about/strategy-vision

OsloMet. (2018). The digital university of the future. In Strategy for digital transformation 2018-2024. Retrieved 25. June, 2020, from https://ansatt.oslomet.no/documents/585743/77463421/Strategy+for+digital+transformation.pdf

Park, J-H., \& Choi, H.J. (2009). Factors influencing adult learners' decision to drop out or persist in online learning. Journal of Educational Technology \& Society, 12(4), 207-217.

Tiller, T. (2004). Aksjonsforskning $i$ skole og utdanning [Action research in school and education]. Kristiansand: Høyskoleforl.

UDIR. (2017). Facts about Norwegian education. Retrieved 4. March, 2019, from http://www.udir.no/in-english/

Weidlich, J., \& Bastiaens, T.J. (2018). Technology matters: The impact of transactional distance on satisfaction in online distance learning. International Review of Research in Open and Distributed Learning, 19(3), 222-242.

Werhner, M.J. (2010). A comparison of the performance of online versus traditional on-campus earth science students on identical exams. Journal of Geoscience Education, 58(5), 310-312.

Woodcock, S., Sisco, A., \& Eady, M. (2015). The learning experience: Training teachers using online synchronous environments. Journal of Educational Research and Practice, 5(1), 21-34.

Zawacki-Richter, O., \& Naidu, S. (2016). Mapping research trends from 35 years of publications in distance education. Distance Education, 37(3), 245-269. 